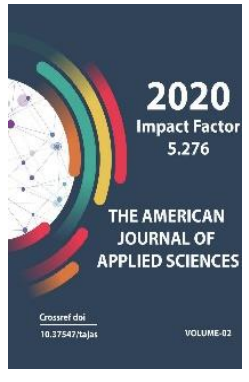

Copyright: Original content from this work may be used under the terms of the creative commons attributes 4.0 licence.

\section{Algorithm For Calculation Of Multi Span Uncut Beams Taking Into Account The Nonlinear Work Of Reinforced Concrete}

\author{
A.T.Mirzaahmedov \\ Dots.Fargona Polytechnic Institutes, Uzbekistan \\ S.G'.G'ulomiddinov \\ Fargona Polytechnic Institutes, Uzbekistan
}

\title{
ABSTRACT
}

An algorithm for calculating multi-span continuous beams is developed on the basis of the integral deformation modulus method. This takes into account the nonlinear and nonequilibrium properties of concrete deformation, the rheological equations of the mechanical state.

\section{KEYWORDS}

Computational algorithm, intermediate supports, canonical equations, concrete, elastic.

\section{INTRODUCTION}

The calculation algorithm is based on the method of integral modulus of
deformations.A diagram of a multi-span continuous beam and the corresponding basic system are shown in Fig. 1. 


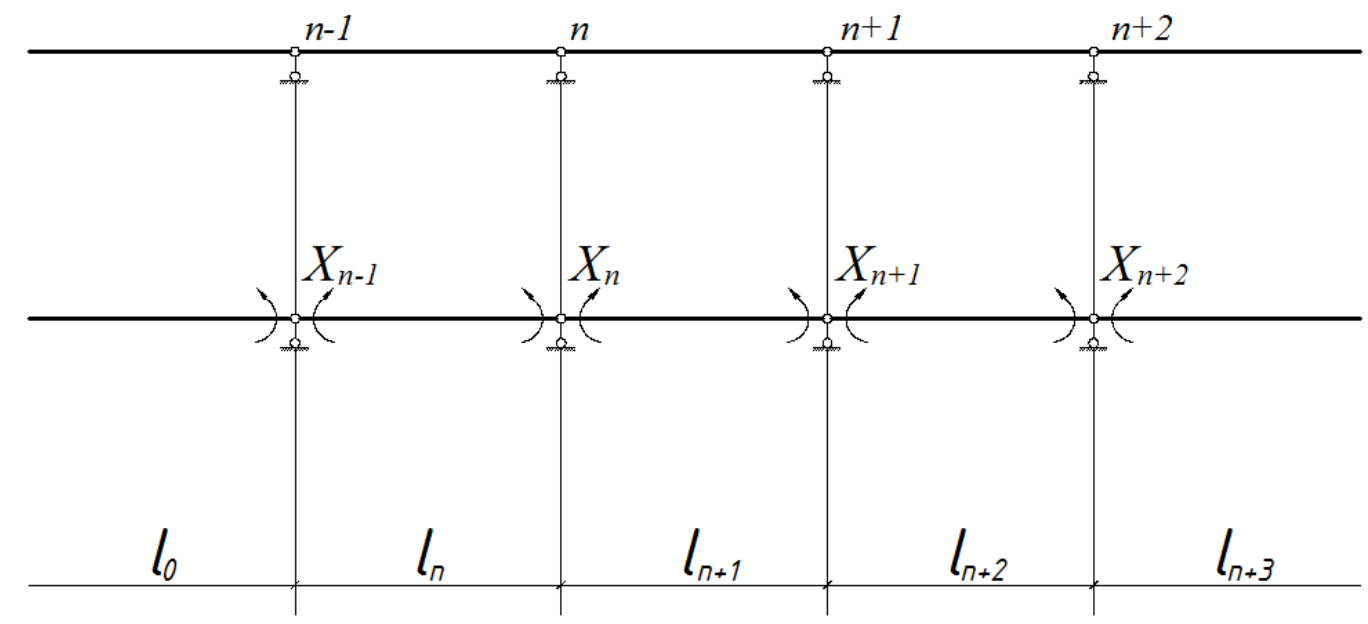

Fig. 1. Non-cutting continuous beam

It is believed that the beam can have variable sections. The load on it is set in the form of moments of the main system. The continuous beam is calculated by the force method, with the basic system composing the moments on the intermediate supports.

The system of canonical equations of the force method consists of equations of the type.

$$
\sigma_{n . n-1} \mathrm{X}_{\Pi-1}+\sigma_{n, n} \mathrm{X}_{n}+\sigma_{n . n}+1 \mathrm{X}_{n}+1+\Delta_{n, \mathrm{p}}=0
$$

The number of such equations is known to be equal to / n-2 /, where $\mathrm{P}$ is the number of spans of a continuous beam.

Taking into account the variability of the stiffness of the elements, the coefficients of the canonical equations can be represented in vice

$$
\begin{gathered}
\sigma_{n . n-1}=\frac{l_{n}}{\mathrm{M}^{3}} \sum_{\kappa=1}^{m} \frac{2 m \kappa-2 \kappa^{2}-m+2 \kappa-2 / 3}{D_{n . \kappa-1}+D_{n . \kappa}} \\
\sigma_{n . n}=\frac{l_{n}}{\mathrm{M}^{3}} \sum_{\kappa=1}^{m} \frac{2 \kappa^{2}-2 \kappa+2 / 3}{D_{n . \kappa-1}+D_{n . \kappa}} \\
\sigma_{n . n+1}=\frac{l_{n+1}}{m^{3}} \sum_{\kappa=1}^{m} \frac{2 m \kappa-m-2 \kappa^{2}+2 \kappa-2 / 3}{D_{n+1 . \kappa-1}+D_{n+1 . \kappa}}
\end{gathered}
$$




$$
\begin{aligned}
\Delta_{n . \mathrm{p}}=\frac{1}{3 m^{2}}\{ & l_{n} \sum_{\kappa=1}^{m} \frac{(3 \kappa-2) \mathrm{M}_{n . \kappa+1}^{0}+(3 \kappa-2) \mathrm{M}_{n . \kappa}^{0}}{D_{n . \kappa-1}+D_{n . \kappa}} \\
& \left.+l_{n+1} \sum_{\kappa=1}^{m} \frac{(3(m-\kappa)+2) \mathrm{M}_{n+1 . \kappa-1}^{0}+(3(m-\kappa)+2) \mathrm{M}_{n+1 . \kappa}^{0}}{D_{n+1 . \kappa-1}+D_{n+1 . \kappa}}\right\}
\end{aligned}
$$

After solving the system of canonical equations of type (I) at each stage of the approximation, the numerical values of the extra unknowns $\mathrm{Xn}$ are obtained. This makes it possible, in any section $\mathrm{n}$, to the value of bending moments for a given approximation number

$$
\mathrm{M}_{n . \mathrm{K}}=\mathrm{M}_{n, \mathrm{\kappa}}^{0}-\mathrm{X}_{n} \frac{\mathrm{K}}{m}-\mathrm{X}_{n-1} \frac{m-\kappa}{m}
$$

Information about the diagrams of bending moments allows you to refine the stiffness of the beam sections, which are necessary for the next stage of approximation and. etc.

The calculation takes into account the nonlinear and nonequilibrium properties of concrete deformation, the rheological equations of the mechanical state, which are written according to S.V. Aleksandrovsky [1].
The algorithm of the above calculation methodology will be performed in the following order.

1. Determination of elastic bending moments: After solving the system of canonical equations (1), elastic supporting bending moments are obtained.

2. Calculation of the section stiffness:

$$
D=E_{b}^{\mathrm{uH}}\left[\frac{b x^{3}}{12}+b x\left(q-\frac{x}{2}\right)^{2}\right]+\beta_{S} E_{S}^{\cdot} A_{S}^{\cdot}(q-a)^{2}+\frac{\beta_{S}}{\Psi_{S}} E_{S} A_{S}\left(h_{o}-q\right)^{2}
$$

Where $E_{b}^{\mathrm{uH}}$ - integral modulus of elasticity of concrete;

b - cross-sectional width;

$x$ - the height of the compressed zone of the concrete section;

$\mathrm{q}$ - distance of the center of gravity of the reduced section from the compressed face;

$\beta_{S} \beta_{S}$ - deformation nonlinearity function of reinforcing steel;

$\Psi_{S}$ - coefficient taking into account the work of tensile concrete between cracks;

$E_{S} E_{S}$ - modulus of elasticity of reinforcement;

$A_{S}^{\prime} A_{S}$ - cross-sectional area of reinforcement;

$a$ - cover height;

$h_{o}$ - useful section height. 
3. Determination of bending moments in any section $\Pi, \mathrm{K}$ :

$$
M_{n . \kappa}=M_{n, K}^{0}-X_{n} \frac{k}{m}-X_{n-1} \frac{m-\kappa}{m}
$$

4. Calculation of the coefficient that takes into account the work of tensile concrete between cracks:

a/при $\quad \mathrm{M}<\mathrm{M}_{\mathrm{bt}}$

$$
\Psi_{s}=a_{g \cdot m}+b_{g \cdot m}\left(\frac{M}{M_{n p}}\right)^{C g \cdot m}
$$

б/при $\quad M>M_{b t}$

$\Psi_{S}=1,3-S \frac{M_{b}}{M}$

Where

$$
M_{b . m}=0,8+W_{b . m} R_{b . m}
$$

Here

$$
\mathrm{W}_{b . m}=0.292 b h^{2}
$$

0.8 - coefficient taking into account the effect of shrinkage on the tensile strength of concrete;

$W_{b . m}$ - elasti c-plastic moment of resistance of the concrete section before cracking;

$R_{b . m}$ - design concrete resistance.

$a_{g . m}-$ coefficient calculated by the formula

Here

$$
a_{g . m}=\Psi_{0}=\left(1+\frac{E_{b . o} J_{b . p}}{E_{S} J_{S}}\right)^{-1}
$$

$E_{S}, E_{b . o}$ - initial moduli of deformations of reinforcing steel and concrete;

$J_{S}, J_{b . p}$ - moments of inertia of the tensile zone of concrete and tensile reinforcement relative to the axis passing parallel to the neutral axis through the center of gravity of the section.

$b_{g . m}-$ coefficient equal

Here

$$
b_{g \cdot m}=\frac{\Psi_{m}-\Psi_{0}}{\left(\frac{M_{m}}{M_{n p}}\right)^{C_{g \cdot m}}}
$$

$$
\Psi_{m}=a_{n . m}+b_{n . m}\left(\frac{\mathrm{M}_{m}}{\mathrm{M}_{n p}}\right)^{C_{g . m}}
$$


$M_{T}$ - moments of cracking for the calculated reinforced concrete section;

$$
\mathrm{M}_{n p}=\mathrm{M}
$$

$C_{g . m}$ - coefficient calculated by the formula

Here

$$
C_{g . m}=\frac{b_{n . m} C_{n . m}}{\Psi_{m}-\Psi_{0}}\left(\frac{M_{m}}{M_{n p}}\right)^{C_{n . m}}
$$

$$
b_{n, m}=-S \frac{M_{b}}{M_{n p}}
$$
load;

$S$ - coefficient characterizing the profile of the bar reinforcement and the duration of the

$$
C_{n \cdot m}=-1
$$

5. Condition check:

$$
\left|\Psi_{s . i}\right|-\left|\Psi_{s . i}-1\right|>\xi
$$

Where $\quad \xi$-a measure of the accuracy of the calculation.

If the specified condition is satisfied, then the calculation ends, otherwise, it is repeated from point 2

6. Calculation of the moment of resistance of a reinforced concrete section:

$$
W=\frac{b x^{2}}{2-\Pi_{\delta}}+\frac{\beta_{S} E_{S}}{\Psi_{S}^{2} E^{b p}} A_{S} \frac{\left(h_{0}-x\right)^{2}}{x}+\frac{\beta_{\dot{S}} E_{\dot{S}}}{E^{b p}} A_{S} \frac{\left(x-a^{\prime}\right)^{2}}{2}
$$

Where $\quad \Pi_{\delta}$-normal stress nonlinearity parameter; $E^{b p}$ - temporary modulus of elasticity of concrete.

7. Calculation of stresses by the formula:

$$
\Im=\frac{M}{W}
$$

8. Calculation of the normal stress nonlinearity parameter:

$$
\eta_{\delta}=1-\left(1-f_{0}\right)\left(\frac{\Im}{R_{b}}\right)^{M_{\sigma}}
$$

Where $f_{0}=\frac{E_{R}}{E_{0}}\left(0<f_{0} \ll 1\right)-$ the parameter of nonlinearity of the relationship between stresses and strains in a uniaxially loaded specimen, determined by the ratio of two tangential deformation moduli in a given loaded mode; 
$E_{R}$ - tangential modulus of deformation at the moment of destruction;

$E_{0}$ - initial deformation modulus;

$m_{6}$ - the parameter reflecting the rate of increase in the curvature of the diagram of normal stresses as the level of the inhomogeneous stress state $/ m_{6}$ grows can be taken equal to $\frac{1}{1,5} m_{\mathcal{N}}$; $m_{M}=5,7-0,005 R_{n p}$

$R_{b}$ - bending strength of concrete.

9. Condition check:

$$
\left|\eta_{\delta . i}\right|-\left|\eta_{\delta . i}-1\right|>\xi
$$

If the specified condition is met, then the calculation ends, otherwise, it is repeated from point 6.

10. Calculation of nonlinearity of deformation of reinforcing steel:

$$
\beta_{S}=\left[1+\eta_{s}\left(\frac{\Im_{s}}{R_{\frac{b}{s}}}\right)^{m_{s}}\right]^{-1}
$$

Where $\eta_{s}$ and $M_{s}$ - deformation nonlinearity parameters;

$\mathfrak{S}_{s}$ - stress determined by the formula

$$
\varsigma_{s}=\frac{M}{h_{0}-\frac{x}{3}} A_{S}
$$

11. Calculation of the height of the compressed zone of a concrete section:

$$
X=\frac{1}{2 A}\left(\sqrt{B^{2}+4 A C}-B\right) ;
$$

Where

$$
\begin{gathered}
A=\frac{b E^{b p}}{1+\eta_{\sigma}} \\
B=\frac{\beta_{s}}{\Psi_{s}} E_{s} A_{s}+\beta_{s}^{\prime} E_{s}^{\prime} A_{s}^{\prime} \\
C=\frac{\beta_{s}}{\Psi_{s}} E_{s} A_{s} h_{0}+\beta_{s}^{\prime} E_{s}^{\prime} A_{s}^{\prime} a^{\prime}
\end{gathered}
$$

12. Condition check:

$$
\left|X_{i}\right|-\left|X_{i-1}\right|>\xi
$$


If the specified condition is met, then the calculation ends, otherwise, it is repeated from point 6.

13. Determination of the value of the temporary modulus of deformation:

$$
\begin{gathered}
E^{b p}=\frac{1}{R_{1}} \\
R_{1}=R_{2}-\frac{1}{\varsigma} \sum_{j=1}^{i}\left[1+\eta_{n}\left(\frac{\Xi_{i}}{R_{b}}\right)^{m_{n}}\right]\left\{\left(C_{0}+A_{0} e^{-J R 4}\right)\left[1-e^{-J(R 3-R 4)}\right]\right. \\
\left.-\left(C_{0}+A_{0} e^{-J R 5}\right)\left[1-e^{-J(R 3-R 5)}\right]\right\}
\end{gathered}
$$

Here

$$
R_{2}=\frac{\varepsilon_{y}}{\mathfrak{S}}+\frac{\left[1+\eta_{k}\left(\frac{\mathfrak{S}}{R_{\sigma}}\right)^{m_{n}}\right]}{E_{M}}
$$

Here

$$
R_{h}=(d-c \alpha) R_{b}
$$

Where $\mathrm{d}=1.25$ and $\mathrm{C}=0,25$ /according to N.F. Davydov and O.M. Donchenko / [3];

$$
\alpha=\frac{x}{h_{0}}
$$

$\mathcal{E}_{\mathrm{y}}=\alpha_{\mathrm{y}} \eta_{4}-$ shrinkage deformation,

Where $\alpha_{y}=\eta_{1} \eta_{2} \eta_{4} \alpha_{y}^{c}$ - limiting relative shrinkage deformation.

Here $\alpha_{y}^{c}, \eta_{1}, \eta_{4}$ - shrinkage coefficients / is taken from table. [2];

$$
\begin{gathered}
R_{3}=m \frac{t-t_{0}}{10}+t_{0} \\
R=i_{1} \frac{t-t_{0}}{10}+t_{0}
\end{gathered}
$$




$$
R_{5}=\left(i_{1}-1\right) \frac{t-t_{0}}{10}+t_{0}
$$

Where

$$
i_{1}=1 \div m
$$

$\mathrm{m}$ - time interval from $t_{0}$ to $t$.

14. Calculation of the integral modulus of deformations:

$$
E^{u H}=\Phi E^{b p}
$$

Where

$$
\Phi=\frac{3+\eta_{\delta}}{2+2 \eta_{\delta}}
$$

15. Calculation of the distance of the center of gravity of the reduced section from the compressed face:

$$
q=\frac{E^{\mathrm{uH}} b x \frac{x}{2}+\beta_{s}^{\prime} E_{s}^{\prime} A_{s}^{\prime} a^{\prime}+\frac{\beta_{s}}{\Psi_{s}} E_{s} A_{s} h_{0}}{E^{\mathrm{uH}} b x+\beta_{s}^{\prime} E_{s}^{\prime} A_{s}^{\prime}+\frac{\beta_{s}}{\Psi_{s}} E_{S} A_{s}}
$$

16. Checking the condition:

$$
\left|M_{i}\right|-\left|M_{i-1}\right|>\xi
$$

If the specified condition is met, then the calculation ends, otherwise, it is repeated from point 2.

17. Checking the condition:

$$
m \gg \xi
$$

If the specified condition is satisfied, then the calculation ends, otherwise $m=m+1$ and is repeated from point 2 .

\section{REFERENCES}

1. S.V. Aleksandrovsky. Calculation of concrete and reinforced concrete structures for temperature and humidity effects (taking into account creep). Stroy, Moscow, 1966.
2. V.M.Bandarenko. Some questions of the nonlinear theory of reinforced concrete. Ed. Kharkov University, Kharkov, 1968.

3. N.F. Davydov, O. M. Donchenko Experimental - theoretical study of concrete resistance under eccentric and 
local compression. "Reinforced concrete structures”, bit 1 (30). Ed. - at KSU, Kharkov, 1964.

4. ACCOUNTING FOR NON-LINEAR WORK OF REINFORCED CONCRETE IN THE ALGORITHMS OF CALCULATION AND DESIGN OFSTRUCTURES. https://usajournalshub.com/index.php/taj et/article/view/1445

5. Mirzaakhmedov A.T., Mirzaakhmedova U.A. (2019) "Algorithm of calculation of ferro-concrete beams of rectangular cross-section with one-sided compressed shelf". Problems of modern science and education. Scientific and methodical journal. № 12 (145). Part 2. Moscow. P.p.50 - $56 . \quad$ URL: https://cyberleninka.ru/article/n/algoritmrascheta-zhelezobetonnyh-balokpryamougolnogo-secheniya-sodnostoronney-szhatoy-polkoy

6. Mirzaakhmedov A.T., Mirzaakhmedova U.A., Maksumova S.M. (2019) "Algorithm for calculation of prestressed reinforced concrete farm with account of nonlinear operation of reinforced concrete". Actual science. International scientific journal. № 9 (26). Moscow. P.p.15-20. URL: https://e64fge97-223d-468f-a5fde095d169621a.filesusr.com/ugd/c22b2f_e 76d3b62ae5b404a8ae4aa16a2cb97e9.pdf

7. Mirzaakhmedov A.T., Mirzaakhmedova U.A. Prestressed losses from shrinkage and nonlinear creep of concrete of reinforced concrete rod systems. EPRA International journal of research and development (IJRD). Volume - 5; Issue 5; May 2020. 588 - 593pp. URL: https://eprajournals.com/jpanel/upload/72 9pm_125.EPRA\%20JOURNALS\%204567.pdf

8. Teshaboyeva N.D.Uluchsheniye struktury i svoystva betona $v$ usloviyakh sukhogo zharkogo klimata gidrofobnoplastifitsiruyushchey dobavkoy. YEVRAZIYSKIY SOYUZ UCHENYKH (YESU)
Yezhemesyachnyy nauchnyy zhurnal.№ 3 (72)/ 20202 chast'

9. Teshaboyeva N.D. ISSPOL'OVANIYe MINERAL'NYKH NAPOL'NITELEY I KHIMICHESKOY DOBAVKI ATSF, PAV POLIFUNKTSIONAL'NOGO

NAZNACHENIYA, PRI PROIZVODSTVE TSEMENTA, MONOLITNYKH I SBORNYKH ZHELEZOBETONNYKH KONSTRUKTSIY .. YEVRAZIYSKIY SOYUZ UCHENYKH (YESU) Yezhemesyachnyy nauchnyy zhurnal.№ 3

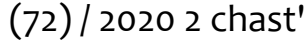

10. Teshaboyeva N. D. Sposob opredeleniya kapillyarnoy pronitsayemosti betona $v$ usloviyakh sukhogo zharkogo klimata. YEVRAZIYSKIY SOYUZ UCHENYKH (YESU) Yezhemesyachnyy nauchnyy zhurnal № 10 (67) / 2019 .7 chast'

11. Teshaboyeva N.D. Ispol'zovaniye mineral'nykh napol'niteley i khimicheskoy dobavki ATSF, PAV polifunktsional'nogo naznacheniya , pri proizvodstve tsementa, monolitnykh i sbornykh № 12 (69) / 20194 chast'.

12. Teshaboyeva N.D.Vliyaniya vysykhaniya Aral'skogo morya i sukhogo zharkogo klimata Tsentral'noy Azii na nesushchiye i ograzhdayushchiye konstruktsii i zdaniy i sooruzheniy.Molodoy uchennyy. №20. (258).May 2019.

13. Teshaboyeva N.D. IMPROVEMENT OF THE STRUCTURE AND PROPERTIES OF CONCRETE UNDER THE CONDITIONS OF DRY HOT CLIMATE HYDROPHOBIC PLASTIC ADDITIVE. INTERNATIONAL JOURNAL OF RESEARCH CULTURE SOCIETY . Monthly, Peer-Reviewed, Refereed, Indexed Journal . Accepted on : 20/11/2019

14. Teshaboyeva N.D. Yuk kŭtaruvchi konstruktsiyalarni loyixalashda seysmik khududlarni e"tiborga olish.FarPI ITZH NTZH . 2019. №1

15. Mirzajonovich, Q. G., Ogli, A. U. A., \& Ogli, KH. A. M. (2020). Influence Of Hydro Phobizing Additives On Thermophysical Properties And Long-Term Life Of 
Keramzitobetona In An Aggressive Medium. The American Journal of Engineering and Technology, 2(11), 101107.

16. Ogli, KH. A. M., Ogli, A. U. A., \& Mirzajonovich, Q. G. (2020). Ways Of Implementation Of Environmental Emergency Situations In Engineering Preparation Works In Cities. The American Journal of Engineering and Technology, 2(11), 108-112.

17. Mirzaahmedov, A. T. (2020). Accounting For Non-Linear Work Of Reinforced Concrete In The Algorithms Of Calculation And Design Of Structures. The American Journal of Engineering and Technology, 2(11), 54-66

18. Ogli, A. U. A., Ogli, KH. A. M., \& Mirzajonovich, Q. G. (2020). Hazrati Imam Architecture The Complex Is A Holiday Of Our People. The American Journal of Engineering and Technology, 2(11), 46-49. 